\title{
Crónica festiva de Ana María González y Zúñiga a la Virgen de Guadalupe: Florido ramo (1747)
}

\section{Festive chronicle of Ana María González y Zúñiga to the Virgin of Guadalupe: Florido ramo (1747)}

\author{
Estela Castillo Hernández \\ Universidad Veracruzana,México
}

Resumen: Se presenta un estudio de la obra poética religiosa de Ana María González y Zúńiga. Se analiza el poema cronístico Florido ramo, que compuso para describir las festividades con las que el pueblo novohispano en 1747 celebró la jura de la Virgen de Guadalupe como patrona de Nueva España. La crónica festiva de González destaca por dos razones: la primera, porque hasta ese momento la mayoría de las composiciones elaboradas en torno a la Guadalupana eran escritas por hombres (su crónica es una excepción a esta costumbre); el segundo motivo es por el buen manejo que hace la autora de varias fuentes, temas, tópicos y motivos literarios barrocos, así como de diversos lugares comunes de la literatura guadalupana.

Palabras clave: Ana María González y Zúñiga, poesía novohispana, crónica festiva, Guadalupana, 1747.

Abstract : This is a study of Ana María González y Zúñiga's religious poetry. I analyze her poem Florido ramo, a chronicle of the 1747 festivities with which New Spain celebrated the naming of the Virgin of Guadalupe as patroness of New Spain. González y Zúníiga's festive chronicle is important for two reasons: first, because until it was written, most compositions on the theme of the Guadalupana had been written by men (therefore, her chronicle is an exception to this custom); the second reason is González y Zúniga's impressive implementation of various sources, topics and baroque literary motifs, as well as common places of Guadalupe literature.

Keywords: Ana María González y Zúñiga, Novohispanic poetry, Festive chronicle, Guadalupana, 1747. 
Según la información hasta ahora encontrada, Ana María González y Zúñiga fue la única mujer novohispana que, durante el siglo XVIII, escribió y publicó una crónica festiva en torno a la Virgen de Guadalupe, la advocación mariana más célebre en América. Parte de su vida se puede reconstruir a partir de los comentarios de sus allegados y de las apostillas que aparecieron en sus poemas publicados. En la "Aprobación" de su crónica Florido ramo, que tributa en las fiestas de María santísima de Guadalupe la imperial corte mexicana, texto sobre el cual se elabora el presente estudio, Juan José Eguiara y Eguren destaca los talentos poéticos de González y Zúńiga, y ensalza el hecho de que su formación literaria se debió al autodidactismo:

este solo Florido ramo de dońa Ana es buen indicio de la ingeniosa y poética abundancia de nuestra patria. Pues éste y otros que ha publicado y publicará, ponen a la vista la fuerza de su ingenio, que sabe brotar tan bellas flores, sin oír maestros ni revolver bibliotecas, ni frecuentar academias, por ser estos empleos ajenos de su sexo (González, 1748: [f. 2v]). ${ }^{1}$

${ }^{1}$ El impreso Florido ramo se compone de ocho folios, pero no está foliado, por lo que se agrega foliación entre corchetes. Asimismo, se numeran los versos de la crónica. La numeración es corrida: inicia con el primer verso de la primera décima ([f. 5r]) y termina en el 680, en la décima 68 ([f. 8v]). A la dedicatoria del poema cronístico se le asignó una numeración independiente (tiene 36 versos, [f. 1v]). En lo sucesivo, toda información proveniente de este impreso se citará sólo con el número de folio o verso en el texto, según corresponda. De este impreso novohispano, así como de los siguientes utilizados en este estudio, se modernizó la ortografía. Esto último deberá tomarse en cuenta al momento del conteo silábico, pues para que algunos versos sean octosílabos se deberán deshacer los hiatos que suponen algunos acentos; ejemplo día o María, entre otros casos. También se cambió la puntuación (se puntuó siempre siguiendo la sintaxis del texto). 
A lo largo de la "Aprobación", el discurso de Eguiara se centra en los talentos americanos y de paso hace referencia a los tomos de su Biblioteca mexicana, la "que tra[e] entre manos" ([f. 2v]). Hay que recordar que el primer tomo de esta magna obra salió a la luz hasta 1755, siete años después de escribir la "Aprobación" del Florido ramo (15 de enero de 1748). En la Biblioteca mexicana, el bibliógrafo dedicó varias palabras a la poetisa, con las que confirmó y amplió su opinión sobre las habilidades literarias de González:

mexicana, de la capital. Unida en honesto matrimonio, del cual tuvo un hijo sacerdote y una hija en las monjas capuchinas, mereció ella misma ser contada entre los moradores del Parnaso. Muy instruida en literatura, entregada a la lectura de libros doctos, dotada de feliz inspiración, y por ésta guiada, escribe frecuentemente, y con facilidad, poemas, no sólo acabados con las normas que prescribe el arte, sino con la agudeza y erudición que las cosas piden, bella y oportunamente dotados. Por ello muy estimada de los sujetos más doctos, compareció entre los principales poetas en los más autorizados teatros que en México, treinta años hace, con aplauso de las musas, por gestiones de Minerva y sin desdén de Apolo, resonaron con suavísimos cantos (Eguiara, 1986: 364365).

Eguiara proporciona datos biográficos significativos de la autora: el lugar de nacimiento, su estado civil, que tuvo, al menos, dos hijos, y la fecha en que su nombre y obra aparecieron por primera vez en el ámbito literario (ca. 1724-1725). ${ }^{2}$ Aunque básicos, estos datos se convirtieron en la principal fuente de información de los

\footnotetext{
${ }^{2}$ Eguiara señala directamente que desde 1724 la autora se encontraba participando en certámenes, dedicados al rey Luis I, aunque no se conservan textos suyos de esa época (1986: 364-365). Aquí esa información se sobreentiende por el "treinta ańos hace"; el punto de partida es 1755 , año de publicación de su Biblioteca.
} 
biógrafos de la escritora durante los siglos XIX y XX; entre ellos José Mariano Beristáin y Souza, quien consigna las mismas noticias en su Biblioteca hispanoamericana septentrional, publicada en 1816 (1980, s. v. Zúniga), y de quien parten algunos estudiosos del XX y XXI para presentar la vida y obra de la poetisa. Eguiara finaliza la nota de la autora con los premios que obtuvo en los diferentes certámenes en los que participó y también señala los opúsculos que publicó.

A partir de estas noticias bio-bibliográficas y de una revisión de sus poemas, se puede dividir la obra de González en dos líneas: religiosa y cívica. Esta última vertiente fue la que más practicó. Casi todos sus poemas cívicos giran alrededor de la figura de Fernando VI, quien subió al trono espańol en 1746. En Nueva Espańa, dos años después de la ascensión del rey (1748), la Universidad de México y el Colegio de san Ildefonso convocaron dos justas literarias para celebrar este hecho (Muriel, 2000: 281-282; Vigil, 1893: XII-XIII). En el certamen de la Universidad, la poetisa concursó con cuatro octavas divididas en redondillas y ganó el tercer lugar en su categoría; sus octavas y los resultados de la justa literaria se publicaron bajo el título: Coloso elocuente que en la solemne aclamación del augusto monarca de las Españas don Fernando (que Dios prospere) erigió sobre brillantes columnas la reconocida lealtad y fidelisima gratitud de la imperial y pontificia Universidad mexicana (1748: 99). Asimismo, la escritora participó con un soneto -por el que fue premiada-, un romance heroico, una canción y una quintilla en el certamen del Colegio de san Ildefonso, justa que se imprimió con el título Cifra feliz de las dichas imponderables que se promete la monarquía española bajo el suspira[do] dominio de su augusto soberano el señor don Fernando VI (1748: 66-67, 180-182, 226-227, 262-263, respectivamente). Sus últimas dos obras, es- 
tampadas en la Ciudad de México en 1750, también se centran en este personaje real. ${ }^{3}$

Ejemplifican la vertiente religiosa practicada por la autora dos composiciones escritas a base de décimas: dos espinelas sobre san Juan de la Cruz y el poema cronístico ya mencionado de la Guadalupana. ${ }^{4}$ En 1726, se canonizó al místico español, por lo que en 1729, en la Ciudad de México, se llevaron a cabo varias fiestas para celebrarlo, entre ellas un certamen poético, que se publicó un año después en el volumen El segundo quince de enero de la corte mexicana. Solemnes fiestas, que a la canonización del mistico doctor san Juan de la Cruz celebró la provincia de san Alberto de Carmelitas Descalzos de esta Nueva España. El tema de la justa era la comparación del santo con Proteo, héroe mitológico caracterizado por revestir diversas formas; así, san Juan, al igual que Proteo, había tomado diversos aspectos, manifestado diferentes virtudes y hecho varios milagros, para reformar la orden carmelita (Jiménez, 1730: 558). González obtuvo el primer lugar del séptimo asunto del certamen. ${ }^{5}$ En sus dos décimas premiadas, la poetisa muestra al lector

${ }^{3}$ Se trata, a decir de Víctor Mínguez Cornelles, de dos crónicas festivas, publicadas con los títulos Enjugado llanto de Melpómene en la solemne jura de nuestro rey y señor don Fernando VI, que Dios guarde. Y regocijo contenido con la muerte del señor don Felipe $V$ (romance heroico) y Resucitadas glorias de la hermosa Calíope en las festivas celebridades de nuestro deseado monarca Fernando VI (1995: 104-105). ${ }^{4}$ Baehr indica que la espinela es "la forma más regular y caracterizadora que la estrofa de diez versos logró alcanzar [en Nueva España], y la única que perduró hasta nuestros días" (1997: 295).

${ }^{5}$ El asunto era el siguiente: "Deseaba el varón justo Francisco Yepes, glorioso hermano de nuestro Proteo [san Juan de la Cruz], verle después de muerto, y quejándose a Dios humildemente, de que mereciéndole otras gracias le denegase la propuesta, le concedió la profesa mano de su liberal misericordia, que lograse sus votos, mirando sólo la carne de san Juan, que veneraba en un relicario, porque fijando después los ojos con esperanza en la certidumbre de las infalibles promesas, se le demostró más bello, en la propia forma, que le conocieron en su vida" (Jiménez, 1730: 655). Las composiciones, además de exponer el tema 
una imagen vívida de lo que observa Francisco Yepes -hermano carnal del santo-, a través del cuerpo de Juan; en ambas composiciones la autora privilegia el sentido de la vista. La poetisa en los primeros cuatro versos de la primera décima retrata a Francisco Yepes un tanto dudoso por el prodigio que observa:

Fijar los ojos intenta

Yepes para asegurar

si lo que llega a mirar

a Proteo le representa.

Más hermoso se le ostenta

cuando ya le llora muerto,

y así no quedando incierto

de que es, en su corazón

lo estampa, y con más razón

obraba por el de-sierto (Tenorio, 2010: 1105).

El nombre secular de san Juan de la Cruz era Juan Yepes Álvarez, por lo que la poetisa elige apelar al hermano carnal de san Juan mediante el apellido paterno de ambos (v. 2). En los siguientes seis versos, Francisco Yepes confirma que es su hermano Juan: "y así no quedando incierto / de que es", es decir, ya no hay duda de que es él. Francisco intenta aprehender esa representación milagrosa que Dios le ha permitido contemplar (vv. 8-9). Finalmente, la autora cierra la décima con un calambur: la palabra "de-sierto" alude, por un lado, a la certeza del milagro y, por el otro, a la necesidad de convencer a un incrédulo. ${ }^{6}$ La segunda espinela se centra en el

mencionado, debían mostrar las figuras de la Virgen María, el Salvador, santa Teresa y otros santos.

"El primer sentido del calambur propone entender "de cierto"; es decir san Juan, el Proteo divino, “obraba”, reproducía, el milagro de la aparición frente a Francisco Yepes, para que él tuviera fe y certeza del milagro; Yepes se convierte en el testigo que evidencia un favor celestial y por ello "con más razón [Proteo, 
cuerpo de san Juan, el cual también debía representar, como solicitaba el certamen, a santa Teresa y a la Virgen María:

\author{
Alegórico en su empresa \\ dio a entender, contemplativo, \\ que el mostrarse allí visivo \\ era hazaña de Teresa, \\ porque cuando su fineza \\ su casto deseo infundió \\ en ella también mostró, \\ obediente, humilde y grato, \\ que en su carne hasta el retrato \\ de una Virgen encarnó (Tenorio, 2010: 1105).
}

En los primeros seis versos de la segunda décima, se destaca que la empresa (el milagro de la aparición) de Juan es alegórica, porque su cuerpo es una extensión de la perfecta fusión que alcanzaron santa Teresa de Jesús y san Juan de la Cruz para renovar la orden carmelita, ya que si bien san Juan reformó la orden y fundó la regla de los carmelitas descalzos, la idea de renovarla y de instaurar una nueva regla surgió de la santa ("su casto deseo infundió", v. 16); por ello, la obra reformatoria de Juan "era hazańa de Teresa” (v. 14); ella era la inspiración, la idea, el impulso, y él, la materialización, la ejecución. Finalmente, la poetisa señala que la carne del cuerpo de Juan e incluso la misma Teresa, por la castidad y pureza

\footnotetext{
san Juan] obraba por él [por medio de él, Francisco] de cierto [verdadera era la aparición, el milagro]". El segundo sentido del calambur propone entender "desierto", que alude a la frase popular "predicar en el desierto", que significa que los "oyentes no están dispuestos [...] para admitir la doctrina y consejos que se les da", por más razones o argumentos que se les presenten (Diccionario de autoridades, s. v. 'predicar en desierto'); en esta lógica, se justifica entonces y se hace necesario ("y con más razón obraba") el milagro de la aparición frente al hermano, pues en un principio duda y se muestra un tanto incrédulo de lo que mira; al final, el hermano se convence del prodigio.
} 
que ambos ostentan, personifican las virtudes de la Virgen María; de ahí que "en su carne hasta el retrato de una Virgen encarnó" (vv. 19-20).

Estas décimas espinelas son muestra del talento que desde temprana época la autora manifestó, pues ambas composiciones son las más antiguas que de ella se conservan. La siguiente ocasión en que González usó públicamente décimas fue en su crónica guadalupana. La obra que se conoce de la autora hasta ahora es la publicada y en ésta se encuentran 70 espinelas. Una revisión de las estructuras usadas por la autora determinó que, con frecuencia, su producción cívica fue hecha en metros de arte mayor, en el que predominaron los versos de once sílabas; mientras en sus creaciones religiosas recurrió al arte menor; ahí imperaron los de ocho. Una vez señaladas algunas de las características más significativas de la obra poética de Ana María González, conviene ahora detenerse en su poema guadalupano.

\section{González y Zúñiga, la cronista de la Virgen de Guadalupe}

Como señala Joaquín Antonio Peñalosa, la poesía fue la primera manifestación que suscitó la Virgen de Guadalupe en territorio novohispano (1984: 12). El 26 de diciembre de 1531, días después de las apariciones de la Guadalupana, que se efectuaron, según la leyenda, entre el 9 y 12 de diciembre, mientras se trasladaba su imagen "del Oratorio del obispado a la rústica ermita del Tepeyac, se cantó este Cantar Mexicano o Pregón del Atabal que compuso en náhuatl don Francisco Plácido, señor de Atzcapotzalco" (Peńalosa, 1984: 12). En el Pregón aparecían dos elementos que se convertirían en motivos o lugares comunes de la poesía guadalupana: flores o rosas para retratar o aludir a la Virgen de Guadalupe, y la idea de una pintura de origen divino, creada por Dios, el gran pintor- 
autor: “[...] Junto al agua cantaba [Santa María]: / soy la planta preciosa de escondidos capullos; / soy hechura del único, del perfecto Dios: / [...] Dios te creó ¡Oh santa María! / entre abundantes flores; / y nuevamente te hizo nacer, / pintándote en el obispado" (González, 2004: 277).

Después de ese Cantar, se compusieron varias obras sobre la Virgen del Tepeyac, entre las cuales figuraban las teatrales y, más tarde, ya en el siglo XVII, los sermones conceptuosos y los tratados de carácter histórico y científico, los cuales intentaban demostrar la aparición de la Guadalupana o bien negarla. Miguel Sánchez (1648), Luis Lasso de la Vega (1649), Mateo de la Cruz (1660), Luis Becerra Tanco (1666) y Francisco de Florencia (1688) son los cronistas e investigadores guadalupanos más importantes del siglo XVII, pues relatan el acontecimiento con base en diversas fuentes y testimonios del XVI, cuando supuestamente se dio la aparición milagrosa (Torre, 2007: 20-21). Varios escritores de los siglos venideros se inspiraron en ellos para componer sus obras. A la par de los tratados, se escribieron textos literarios que sólo pretendían cantar la milagrosa aparición o festejar algún hecho relacionado con el culto guadalupano.

Los escritores guadalupanos encontraron materia poética en tres sucesos memorables que ocurrieron en el segundo tercio del XVIII: el primero, acaecido en el año de 1737, cuando, debido a la peste de matlazáhuatl que asoló a la Ciudad de México y a otras poblaciones, se aclamó a la Guadalupana como patrona protectora de la Ciudad de México; el segundo, en 1746, cuando "el culto alcanzó su máxima expresión” (Goicochea, 1994: 32), ya que los delegados de las diócesis novohispanas proclamaron a la Virgen su patrona universal. A raíz de esta proclama, al año siguiente (1747) se festejó el nombramiento de la Señora de Guadalupe como patrona de la América Septentrional, es decir, de todo el territorio que comprendía el virreinato de Nueva España (Peñalosa, 1988: 
33-34), y el último, en 1754, cuando el Vicario de Cristo, Benedicto XIV, aprobó el patronato de la Virgen del Tepeyac sobre la nación mexicana, gracias a las labores del jesuita Juan Francisco López. El papa además concedió los privilegios para su culto y santuario.

Los escritores que se encargaron de ensalzar el nombre de la Guadalupana fueron sacerdotes en su mayoría, quienes o bien eran miembros del cabildo de la catedral y de la Universidad de México, o eran integrantes de la Compañía de Jesús, por lo que llama la atención que a la poetisa González, quien no pertenecía a alguna orden o grupo religioso, se le haya encargado narrar las fiestas de la solemne jura que hizo Nueva Espańa para nombrar a la Guadalupana patrona de la América Septentrional, el segundo de los sucesos memorables del siglo XVIII. La autora describe la distinción que hizo el pueblo mexicano a la madre de Dios en 68 décimas espinelas, las cuales forman un poema cronístico, en el que se detallan fechas, actos (cultos) y acompańantes, en un orden secuencial. ${ }^{7}$ Tales solemnes fiestas se efectuaron el 12 de diciembre de 1747 y la descripción poética se publicó un año después en la Ciudad de México con el título: Florido ramo, que tributa en las fiestas de María santísima de Guadalupe la imperial corte mexicana, en la Imprenta del Nuevo Rezado de María de Ribera. Apenas ocho folios contienen la narración y en la portada del impreso se presenta un grabado de la Morenita: la imagen es la misma que aparece en el manto del Tepeyac y que la poetisa se encarga de describir en sus décimas.

${ }^{7}$ Florido ramo cumple con las características esenciales de una crónica: una narración, con cuerpo poético, que sigue el orden consecutivo de los acontecimientos; sin embargo, durante el periodo colonial se llamó crónica, o historia, al texto que trataba sobre la vida del rey o de personas heroicas (Diccionario de autoridades, s. $v$. 'chrónica'); estrictamente, el poema de González forma parte del género poesía de relaciones, usado para relatar fiestas civiles o religiosas en los Siglos de Oro y que fue practicado asiduamente en Nueva España. 
Antes de comenzar el análisis de la crónica, es importante destacar que aunque los cantores de la Guadalupana usaron diversos metros y estructuras para escribir sobre la Virgen, durante la Colonia se privilegió la octava real, el soneto y el romance -octosilábico y endecasilábico- (González, 1995: 15-16; Torre, 2007: 1103). ${ }^{8}$ Son pocos los textos acerca de la Guadalupana escritos en décimas durante el virreinato; en el Seiscientos, Alonso Ramírez de Vargas hace sus Décimas a la imagen de Guadalupe (1690). En el siglo XVII se registran dos textos significativos: las espinelas de González y la obra anónima Espejo de conversión (1762). No era usual escribir sobre la Guadalupana en décimas en esa época, al contrario de lo que sucederá en los siglos XIXy XX,9 por lo que cabe suponer que la elección de la autora de hacer espinelas quizá se deba a las cualidades de esta estrofa, pues $a$ ) se podía usar de manera autónoma -por su concisión era adecuada para la agudeza del epigrama, recuérdense las décimas de Góngora y las de González dedicadas a san Juan de la Cruz- y b) "como unidad estrófica en conjuntos extensos” (Baehr, 1997: 301). La necesidad de elaborar un texto fluido, continuo, secuencial, pudo influir para que la poetisa eligiera tal estructura. Asimismo, el hecho de que la décima clásica se encontraba a la par del soneto (Baehr, 1997: 300), pudo ser decisivo para que González la eligiera y la encontrara digna

${ }^{8}$ En octavas reales se encuentran la Primavera indiana (1668) de Carlos de Sigüenza y Góngora, la Octava maravilla (1729) de Francisco de Castro, la dedicatoria "A María santísima Señora nuestra de Guadalupe" (ca. 1762) de Juan José de Arriola, La milagrosa aparición (1769) de José Lucas Anaya; en sonetos, el célebre sobre la metamorfosis de las rosas de Luis de Saldoval y Zapata (1688), y las Flores guadalupanas (1785) de Antonio José Plancarte; en romance, el anónimo Deprecación a María santísima (1736) y Demostración del romance mudo de Antonio Manuel Valdés (1780), entre otros.

${ }^{9}$ Basta ver las antologías de Joaquín Antonio Peñalosa dedicadas a la poesía guadalupana de los siglos XIX y XX para corroborar el éxito que tuvo la décima de carácter popular en esos periodos. 
para alabar a la Virgen del Tepeyac, aunque esto suponía un desvío de las formas que tradicionalmente se usaban para glorificarla en los siglos XVII y XVIII.

El título Florido ramo se refiere, por un lado, al ramillete o manojo de flores con el que la autora y el pueblo mexicano obsequian a la Virgen y, por el otro, a la flor milagrosa de América, como llama Eguiara a la Virgen del Tepeyac en las preliminares del poema: "Y siendo el título del poema Florido ramo, por dedicado al milagro de las flores y flor de los milagros de nuestra América, la floridísima imagen Guadalupana” (González, 1748: [f. 3v]). Nótese que Eguiara atiende a la convención literaria de aludir a la Virgen de Guadalupe mediante flores. Asimismo, este "ramo florido" se compone del conjunto de versos hechos por la poetisa y de las acciones insignes realizadas por los novohispanos en 1747 en favor del nuevo patronato; ambos, poesía y labores, son flores, por su belleza y acierto; porque representan lo mejor que produjo Nueva Espańa en torno a la Guadalupana.

Florido ramo inicia con una dedicatoria, cuya forma métrica es la del romance heroico con asonancia en -ue. El romance heroico -construido a partir de endecasílabos- era practicado asiduamente por González (recuérdense los romances que escribió para Fernando VI); también, como ya se indicó, fue usado para glorificar a la Virgen del Tepeyac, pues al ser el endecasílabo el verso clásico de la poesía culta española y la Guadalupana un asunto sublime y solemne, se trataba de mantener el decoro entre la forma y el contenido. En total son 36 versos divididos en 9 cuartetas, en los que la autora consagra su poema "A la purísima reina María santísima de Guadalupe":

A ti hermosa Raquel, Sara divina, llega humillado mi confuso numen, si remontado a impulsos de su afecto puede subir a la florida cumbre. 
Tú, prudente Abigaíl, eleva el vuelo de mi atrevida pluma, que no pude contener el orgullo de su empresa con el despeño cruel que le propuse. Recibe de una humilde esclava tuya lo que el alma en deseos, Señora, encubre, aunque bien sé que obsequios tan indignos al humo de la aroma se destruyen. Pero llegando a tan excelsas aras la menor oblación consigue lustre, que se elevan al trono majestuoso sacrificios que humildes se conducen. $\mathrm{Si}$ acaso por indigna aquesta ofrenda se halla incapaz de que tu agrado ocupe, rendimientos angélicos son cortos para el divino ser de tus virtudes. Esta pequeña empresa, que tan sólo a una silvestre flor amor reduce, en el jardín florido de tu imagen sea el riego de tu gracia quien la ilustre. Tributo humildemente a tu hermosura de todos tus esclavos gratitudes, siendo yo para el tierno sacrificio la sierva que ministra los perfumes. No desprecies, Señora, aquesta ofrenda, porque va por mi mano, que, aunque inútil, no desmerece, que jamás el vaso al licor soberano quita el lustre. A tus divinas plantas, pensil sacro, es justo que una esclava te tribute, para el cuadro divino de tu imagen, flor que tu riego fecundó en mi numen (vv. 1-36).

La poetisa alude a tres heroínas de la Biblia en las primeras dos cuartetas: Raquel, esposa de Jacob y madre de José y Benjamín 
(Génesis 29); Sara, esposa de Abraham y madre a sus noventa años; además de que engendró reyes de pueblos (Génesis 17), y, finalmente, Abigaíl, quien fuera primero esposa de Nabal, un hombre egoísta e insensato, y después del rey David (1 Samuel 25). Por ser mujeres ejemplares, sus nombres se transforman en tres epítetos para designar a María y sus virtudes: belleza, divinidad y prudencia. El tres es simbólico, pues tiene su correspondencia con la Trinidad: una tríada de mujeres por las tres personas de Dios (vv. 1-8). A María, revestida con el nombre Guadalupano, dedica González su poema cronístico.

La escritora recurre a la captatio benevolentiae -figura retórica mediante la cual el autor solicita a su público que sea benevolente con él y su obra- desde el segundo verso del romance; no lo hace para justificar sus errores e imperfecciones ante los oyentes o lectores, sino para excusarse frente a la Virgen María. Al hacerlo, evidencia la virtud de la humildad, tan importante en la doctrina cristiana. Aquí cabe destacar que según la tradición grecolatina para obtener la inspiración poética se debía apelar a Apolo o a las musas, que tenían su morada en el Parnaso; pero para algunos cantores de la Guadalupana, como González, el numen, es decir la inspiración poética (v. 2), se alcanzaba en el Tepeyac - "florida cumbre” (v. 4)- por gracia de la Virgen. ${ }^{10}$ La tradición grecolatina también indicaba que, además de las musas, el agua que nacía en

${ }^{10}$ Como la convención era invocar a las musas, Carlos de Sigüenza y Góngora
así lo hace en su Primavera indiana, al solicitar inspiración a Calíope y Talía para
cantarle a la Guadalupana (Peńalosa, 1987: 146-168); en cambio Francisco de
Castro, en su Octava maravilla, invoca a la Morenita y le nombra primero nueva
Calíope y después décima musa, pues supera a las nueve conocidas: "Tú, la que,
numen décimo, no al coro / vulgar creciste de las musas nueve, / cual Safo; si
cual tú, la que canoro / número y numen al querub promueve, / a cuya planta
bebe aquel sonoro / castalio instinto, que a los otros llueve; / tú del Parnaso
empíreo, tú María, / décimo coro y cuarta jerarquía" (103). Como era común
en la poesía culta, las octavas reales de Sigüenza aluden a la mitología y literatura 
la fuente Castalia y en el río Permeso, ubicados en el Parnaso, eran otra fuente para obtener la inspiración (Martin, 1998: 102), por lo que la poetisa asocia la gracia de la Virgen - "riego de tu gracia" (v. 24)-, con el líquido que los poetas, como ella, bebían para obtener el numen poético.

En la séptima cuarteta aparece el motivo guadalupano de la flor para retratar a la Virgen del Tepeyac. Así, la autora llama "jardín florido" (v. 23) y "pensil sacro" (v. 33) a la imagen o "cuadro" de la Guadalupana; de esta manera alude a la tilma de Juan Diego, en la que, según la leyenda de las apariciones, se formó la figura de María a partir de las flores. La poetisa juega con diversos usos metafóricos del término flor: flor, aunque silvestre, le llama a su obra poética, sus décimas; flor es la Virgen y flores son las que componen el manto sagrado.

La captatio benevolentiae continúa a lo largo del romance. La autora se califica como esclava y sierva, y utiliza varias metáforas para subrayar su inferioridad -flor silvestre (v. 22); "indigna ofrenda" (v. 17); "pequeña empresa" (v. 21)-. Para finalizar, la poetisa señala que su numen llega "confuso" a las plantas de la Virgen de Guadalupe, por lo que le pide que se apiade y reciba su obra, la cual sólo con su afecto podrá escalar el nuevo Parnaso. El romance se encuentra relacionado con las dos primeras décimas que abren la crónica. Ahí la autora manifiesta que no quiere el numen que nace de Calíope -musa de la poesía épica- o de Clío -musa de la historia; ambas aquí aludidas porque son generadoras de inspiración. Tampoco desea beber el agua de la fuente Castalia ni del río Permeso: "No de Calíope fingida / busco influjos elocuentes, / no pretendo los torrentes / de Permesia envanecida. / No a Helicona derretida / solicita mi instrumento" (vv. 1-6). Y si no pide la inspiración de las musas, que viven en el monte Helicón -otro nombre

clásica; por su parte, De Castro y González siguen citando tales personajes, pero trastocan la convención de acudir a ellas para obtener el numen. 
del Parnaso-, es porque tiene mejor fuente: la Virgen María ("que más soberana Clío / tengo yo en mi pensamiento”, vv. 9-10). En la siguiente décima, la poetisa continúa elogiando a la Virgen por ser fuente inspiradora, así la llama "divina Acidalia”, "más pura Castalia”, "del Ebro encanto” (vv. 12-17). Las metáforas usadas por la autora para apelar a María se relacionan con manantiales o ríos célebres: Acidalia era el nombre que se le daba a la fuente sagrada de Venus (Vega, 1777: 455); Castalia era fuente del Parnaso; Ebro era el río caudaloso de España. Todo ello sirve a la cronista para indicar a su lector que la verdadera musa es la Señora de Guadalupe y que su "empresa métrica" es fruto de su inspiración (vv. 18-20).

Con la tercera décima se inicia propiamente la crónica; ahí, se señala la fecha de la jura (12 de diciembre de 1747): "Once veces disparó / rayos Febo en tierna salva, / y once veces lloró el alba / perlas que el diciembre heló. Once veces tributó / Morfeo ensayos a la parca” (vv. 21-26). Para indicar los días, la autora recurre a Febo, otro nombre para Apolo, dios del fuego solar; se entiende que once veces había salido el dios del sol en su carruaje para iluminar el mundo, esto es, que habían pasado once días cuando llegó el día de la "jura de María”. Por medio de la figura de Morfeo, dios del sueño, se señala que también habían pasado once noches: en once ocasiones Morfeo había pasado su velo somnífero en los mortales y con ello había simulado (ensayado) la muerte del mundo; finalmente, para precisar los meses, se anuncia que el alba había llorado "once veces" perlas antes que diciembre las helara. Once perlas, once rayos y once ensayos de Morfeo, por los once meses pasados y los once días y noches transcurridos, antes del esperado 12 de diciembre.

Después, se menciona la concurrencia tan copiosa que saluda a la Virgen del Tepeyac y se aplaude que sea la jura de María durante el gobierno de Fernando VI, quien apenas un año hacía que había subido al trono (vv. 31-40). Dan la bienvenida a la Virgen cantos 
dulces ("motetes") y música; cohetes tonantes y calificados de "gallardos”, por los múltiples juegos de colores y luces que hacen en el cielo ("esfera"), y repiques de campanas, cuyos sonidos repetidos (desbocados) parecieran lenguas, voces, que pregonan la llegada de la Guadalupana como patrona de toda Nueva Espańa. Todos ellos le hacen "salva" (saludo):

Con bulliciosos arietes

le hacen a María la salva, y a la primer voz del alba, entonan dulces motetes. Las gallardías de los cohetes en la esfera se colocan, y cuando a las torres tocan, formando fogosas filas, se hacen lenguas las esquilas, las campanas se desbocan (vv. 51-60).

Apenas concluye la bienvenida, una fuerte lluvia cae sobre el valle de México: "Se entoldó el cielo, no acaso, / luego que pasó la salva, / que a vista de mejor alba, / se fue a poner al ocaso" (vv. 7174). El cielo, azul y despejado, se cubrió de nubes ("entoldó”), por ello se indica que se fue a ocultar ("al ocaso"). Tres décimas (7, 8 y 9) dedica la autora para exaltar el acierto divino de "enviar del cielo tanta agua, / que se anegaba la corte” (vv. 79-80). Para la poetisa, si una fuerte lluvia había caído sobre la ciudad ("borrasca nociva”, v. 95), no era "acaso" (v. 72), es decir, no era casualidad, sino una manera más de probar al pueblo mexicano, al que la Virgen María en ocasiones pasadas había protegido, y por cuyo favor le habían dado el título de "la secadora de aguas". Así, el agua incentiva a los novohispanos a seguir manifestando su afecto mediante cantos sagrados, adoraciones, súplicas y ofrendas; el pueblo ensaya (practica) cultos (manifestaciones exteriores de devoción) en homenaje 
a la Guadalupana: "En tormenta tan festiva / los ánimos no desmayan, / antes los cultos ensayan / a la devoción más viva" (vv. 91-94). Pese al clima, la celebración prosigue y la algarabía de los habitantes no espera:

Salió un majestuoso carro

con soberano despego,

y en él se hallaba a Juan Diego

triunfos cantando bizarro.

Con amoroso desgarro

los pulqueros convidaban

a las fiestas, y adornaban

el paseo galas costosas,

$\mathrm{y}$ con las piedras preciosas

muchas perlas engastaban.

Empezose el novenario con gran pompa y mayor fe,

$y$, a pesar del tiempo, a pie caminan para el santuario.

A aquel divino sagrario

va a hacer su día, dando ejemplo

el cabildo $-\mathrm{y}$ yo contemplo-,${ }^{11}$

la ciudad y Real Audiencia,

que fueron con su excelencia,

que María los llamó al templo.

Siguió a hacer su feliz día

cada religión sagrada,

alternando en la calzada

cultos fieles a María.

Con reverente porfía

unas a otras se excedieron;

${ }^{11}$ Nótese que aquí la poetisa se asume como testigo de la procesión. 
conforme se siguieron

dulces glorias entonaron,

los oradores oraron

$\mathrm{y}$ todos gracia pidieron.

Todo el pueblo en regio ornato

daba a la Señora culto,

y por gozar del indulto

aclamaba al Patronato (vv. 101-134).

Es un tiempo de fiesta y la ciudad se encuentra engalanada con numerosos adornos y tapices. La procesión, que se compone por un carro con una estatua de Juan Diego, el cabildo eclesiástico, la Real Audiencia y las órdenes religiosas, se dirige hacia el santuario (vv. 101-104). Todos en calidad de peregrinos acuden para agradecer la potestad y auxilio de la Virgen, pues una década antes los había salvado de la epidemia del matlazáhuatl (1737).

Después de representar la ciudad y a sus habitantes jubilosos, la autora se centra en el santuario de la Guadalupana, ubicado en el cerro del Tepeyac; su descripción permite al lector adentrarse al templo, junto con la procesión. Primero detalla el arco triunfal que se encuentra a la entrada del templo. El arco tenía dos portadas y en una de ellas se encontraba pintada una imagen de María (vv. 141-160). El templo estaba decorado con metales preciosos y terciopelos púrpura (ambos elementos simbolizan poder y realeza), por eso es llamado "fiel tesoro, / [ya que] las opulencias retrata" (vv. 161-162). La poetisa se detiene en ofrecerle al lector una escena tanto de la devoción del pueblo como de la majestuosidad del recinto, manifestaciones que tienen un solo fin: glorificar y honrar a la madre de Cristo. Por su valor y estima, púrpura, oro y plata son obsequiados a la reina de los cielos: "Desde el presbiterio al coro, / guarnece de oro el desvelo / al purpureo terciopelo, / y es, cuando al templo reviste, / la primer vez que se viste / de regio 
color el cielo (vv. 165-170). Tal es la cantidad de tela púrpura en el recinto, que cubre cada uno de los espacios que componen la iglesia; para destacar aún más el esplendor del templo, la autora cierra la décima con una imagen hiperbólica: es la primera vez que el cielo se cubre de rojo, pues el templo que reviste o representa la figura de la Virgen, que, al mismo tiempo, es la reina de los cielos, se encuentra tapizado de terciopelo rojo.

González también se detiene en describir la multitud de velas que alumbran el santuario. Éstas son necesarias para celebrar la misa, que por regla no puede ser efectuada sin luz, símbolo de la divinidad. Para indicar la cantidad de piezas, la poetisa recurre a una hipérbole muy socorrida, en la que la luz del recinto supera a la del día: "y dando culto a María / cirios y hachas [vela grande compuesta de cuatro más] se engolfaban / hasta los cielos, y daban / envidia a la luz del día” (vv. 187-190).

La autora prosigue su descripción del templo y detiene su mirada en el altar mayor, donde se encuentra la imagen de la Guadalupana. La figura de la Virgen se representa en trece décimas (de la 20 a la 32) y son de las más afortunadas con las que cuenta el texto, pues, además de que en ellas aparece otro de los motivos principales de la poesía guadalupana: la descripción de la imagen de la Morenita, se hilan varios recursos y tópicos de la literatura para presentarla detalladamente y que los lectores casi puedan verla. Desde la décima 20, González apela al lenguaje pictórico: aparejo, lienzo, lejos, línea, raya, sombras, claros, coloridos y pincel, para describir el manto. Dada la polisemia de los términos usados, éstos permiten destacar, por un lado, el aspecto físico del manto y, por el otro, ensalzar varias virtudes de la Virgen, Dios y la imagen religiosa: 
El lienzo sin aparejos, ${ }^{12}$

que de cáñamo tejido

eligió Dios, hoy se vido

dándole sombra a los lejos.

Con celestiales reflejos

echó las líneas de parte

el pincel, por que descarte

los coloridos que nombra,

y dando luz a la sombra,

pintó los claros con arte (vv. 191-200).

Como en el Pregón del Atabal, Dios asume la figura del pintor, "Artífice sagrado"; se vuelve autor del retrato de la Virgen, por lo que en el poema se detalla su proceder al momento de pintarla: Él dibuja, delinea, traza, selecciona y mezcla colores para producir una verdadera obra de arte. Se aclara que el material elegido para pintar a la Virgen fue rústico y que en su fábrica no hubo intervención humana: "lienzo sin aparejos" (v. 191). La autora quiere destacar la idea de que pudiendo Dios escoger una tela fina, optó por una hecha a base de cáñamo, y con esa elección honró al pueblo novohispano, pues prefirió un producto mexicano (ayate), sobre otro de nacionalidad distinta. Además, se señala la maestría con la que procedió para usar los colores; así, oscureció o dio sombras a las partes menos importantes del lienzo, a "los lejos" (v. 194), y colorió o puso "claros" en la imagen central, la Guadalupana (vv. 195-200). Con acierto e ilustre talento, el Pintor Divino colorió e

${ }^{12}$ El "aparejo" era la técnica usada por los pintores para preparar o imprimir una tela antes de comenzar su labor. "Sombra" o "sombras" es el uso del color oscuro para dar profundidad a los objetos. Los "lejos" en una pintura son las partes de ésta que representan los objetos lejanos o en perspectiva. Los "claros" son porciones de luz que bañan la figura o una parte de la pintura (Diccionario de autoridades, s. v. 'aparejo', 'sombra', 'lejos', 'claro'). 
iluminó el cuerpo de la Virgen; y al hacer esto, dio luz y esperanzas al mundo.

Para representar a la Virgen Guadalupana, la autora sigue la forma tradicional petrarquista que se usaba para representar el cuerpo humano, en especial el de una dama: la descripción es de arriba hacia abajo, por lo que inicia con la cabeza y termina con los pies; asimismo, el paradigma de la mujer angelical era con cándida piel y cabellera rubia. Sin embargo, González se desvía de este último rasgo, pues aunque primero presenta el cabello de la Virgen (como lo dictaba el modelo), dado que el de la Guadalupana es negro y no rubio, recurre al ébano (por ser ésta una madera preciada) para destacar su color oscuro. La cabellera está adornada con flores, que por su colorido la hacen resplandecer. Después, se centra en el rostro y se acerca a las cejas, ojos, nariz, boca y mejillas; luego, el cuello, las manos y los dedos. Siguiendo la tipología petrarquista, muestra la blancura de la piel, la cual es comparada con tres flores blancas: azucena, lirio y jazmín. Éstas eran las flores por excelencia para aludir al candor de la piel; de igual forma, era una metáfora común aludir a la rosa para señalar los pómulos rojos. Finalmente, se detiene en el talle del cuerpo y los pies, sepultados bajo la túnica:
Con peregrino ${ }^{13}$ desvelo,
Dios de precio el pelo sube, por que de la vasta nube hiciese raya a su anhelo.
El ébano vino a pelo, mas con tantos resplandores, que en peregrinos colores el Artífice sagrado, para su hermoso tocado, prendió el pelo en bellas flores.

${ }^{13}$ Nótese que el término peregrino es utilizado a lo largo de estas décimas en su sentido de rareza, de especial. 
Para el rostro peregrino, con misteriosa atención, dio al blanco (en la encarnación) un colorido divino.

Así el Artífice fino retrató con bizarría las cejas, y en simetría, iris, que aplacan enojos, siendo niñas de sus ojos los dos ojos de María.

Del soberano pensil tomó la hermosa azucena, y la nariz enajena aromas al bello abril.

Fue ésta pintada a perfil, y la boca, que retoca $[\ldots]$

[...] El Artífice que, franco, las mejillas delineaba, no maravillas mezclaba, que para hacer sus mejillas, con ser de Dios maravillas, sólo la rosa rozaba.

Con peregrino destello el pincel diestro adelanta, a tornos de su garganta, los candores de lo bello.

Paraíso se juzga el cuello; la mano, en lo soberano, es un poderoso arcano, en que muestra a manos llenas lo puro en cinco azucenas 
por tenerlas de su mano.

La túnica el cuerpo oculta, pero lo airoso del talle descubre, aunque el pincel calle, que el Artífice se indulta.

Hermosa planta sepulta el pie, y en tan raro asunto se halla de gracia un conjunto, pues de gloria, hecho no acaso, de su Concepción el paso primero fijó en un punto (vv. 201-226, 235-260).

La poetisa supedita la descripción de la imagen al lenguaje poético de la época; de ahí que no se destaque el color moreno de la Virgen, pues, según los códigos petrarquistas, entre más blanca era la piel de una mujer, más virginal parecía. La autora al seguir las metáforas tradicionales intenta destacar las virtudes de María y recordarlas al lector: su doble pureza. Dos veces fue pura, pues, por un lado, dio a luz a Jesús siendo virgen y, por el otro, cuando ella fue concebida no la alcanzó el pecado original. La doctrina de la Inmaculada Concepción ${ }^{14}$ aquí se señala en los últimos versos de la décima 26, en la que se indica que su concepción inmaculada es un "hecho, no acaso" (v. 258); es decir, efectivamente sucedió y no hay duda de ello.

Los equívocos que permite el término maravilla-hecho extraordinario y la planta oriunda de México, cuyas flores son púrpura y con algunas manchas- destacan de nuevo la pureza de la Virgen, pues el pintor divino no mezclaba maravillas, sino sólo usaba rosas para colorear las mejillas. Tales equívocos, así como la décima 27, que sigue a la descripción de los pies, sirven también para privilegiar la rosa como única flor en el manto, lo cual fue motivo de

${ }^{14}$ La doctrina de la Inmaculada Concepción se volvió dogma hasta el siglo XIX. 
debate en el período colonial. La tradición señalaba que Juan Diego había recogido diversas flores, pero los escritores guadalupanos usualmente sólo aludían a la rosa, por el antiguo vínculo que había entre la Virgen María y la reina de las flores, que databa de la Edad Media. Francisco de Castro y José Antonio de Villerías y Roelas defendieron la idea "de haberse consumado el milagro con una gran diversidad floral" (Castro, 2012: 28); así como "la existencia de rosas mexicanas", pues algunos peninsulares argumentaban que las rosas en la tilma eran de origen español. Pese a la disputa, algunos cantores, ${ }^{15}$ como González, continuaron enalteciendo la rosa

${ }^{15}$ Entre los muchos autores que escribieron sobre el asunto, se encuentran Luis de Sandoval Zapata y sor Juana Inés de la Cruz, quienes exaltaron la presencia de esta flor en la tilma de Juan Diego en dos sonetos. La composición del primero se titula "A la transustanciación admirable de las rosas en la peregrina imagen de nuestra Señora de Guadalupe. Vencen las rosas al fénix". Ahí, se compara la rosa con el ave mitológica, pues esta flor, al igual que el fénix, viene a sucumbir en el manto para renacer en la figura de María: "Más dichosas que el fénix morís, flores; / que él, para nacer pluma, polvo muere, / pero vosotras para ser María" (Castro, 2012: 286). Sobre el poema, Alfonso Méndez Plancarte indica: "Mueren las rosas en la tilma del Indio, pero mueren para renacer enaltecidas. Las rosas han cambiado su vida vegetal, el aliento de ámbar que respiraban, en otra vida y otro aliento mejor" (Sandoval, 2005: 38). El soneto tuvo tal éxito, que pronto creó imitadores, entre los cuales se hallan Manuel Antonio de Valdés y José Mariano Acosta Enríquez (Osorio, 1991: 182-183); asimismo, la composición se publicó en la edición de La estrella del norte de México de Francisco de Florencia (1688) y en la edición príncipe de la Octava maravilla del jesuita Francisco de Castro (1729). Este último libro mereció que sor Juana le dedicara su único poema con tema guadalupano, conocido por "Alaba el numen poético del padre Francisco de Castro, de la Compañía de Jesús, en un poema heroico en que describe la aparición milagrosa de nuestra Señora de Guadalupe de México, que pide la luz pública”. A decir de sor Juana, si el cielo había hecho el milagro de copiar la imagen de la Guadalupana en la tilma, nuevamente cumplía la proeza, pues De Castro trasladaba la historia de la Virgen del Tepeyac a versos sin igual. El término maravilla permite a la monja establecer un juego entre el título del poema de Francisco de Castro, su talento y la aparición milagrosa. 
en el manto del Tepeyac: "[...] y la rosa clama / por llevarse aquí la fama" (vv. 266-267).

La poetisa con la figura de san Miguel cierra la descripción de la imagen guadalupana: el arcángel, "hecho un serafín" (v. 291), se ha colocado a las plantas de la Virgen para custodiarla (vv. 271-300). Los astros y el arcángel rinden pleitesía a la Guadalupana: el sol, "con diez peregrinos rayos" (v. 272) corona su cabeza; la luna sostiene sus pies (símbolo mariano) y el arcángel es un "atlante", pues le sirve de sostén. Al mencionar a san Miguel, la autora también rememora la épica batalla contra el mal (recuérdese que el arcángel arrojó del cielo a Satanás) y el triunfo de Dios y su Iglesia.

Las estrofas anteriores buscan exaltar la aparición milagrosa otro de los motivos de la poesía guadalupana- y dar fe del honor que recibieron los novohispanos: "La América arrodillada / se notó a sus pies gustosa, / su sombra buscando ansiosa, / y en sus peregrinas alas / halla entre floridas galas / la aparición milagrosa" (vv. 355-360). También, las décimas dan fe de que la imagen es copia fiel de la Virgen María y que su hechura es de origen divino. Si la poetisa dedica varias espinelas para retratar a la Guadalupana, es con el objetivo de que todos los habitantes de la América septentrional vuelvan a ver consumado el milagro de la pintura del Tepeyac y para mantenerlo vivo por siempre en la memoria. ${ }^{16}$

El tiempo siguió su curso y después de presentar el cuadro de María, la poetisa señala que la misa se llevó a cabo y se repartió la comunión (décima 33). Con la misa y el sermón se concluía la celebración. Luego de recibir el cuerpo de Cristo, salió la procesión del Tepeyac y se dirigió a la ciudad de nuevo. La poetisa no deja de

\footnotetext{
${ }^{16}$ Para no dejar lugar a dudas de la aparición, la autora indica que la Virgen se vuelve a presentar ante el apóstol Tomás, para que él, como todos los incrédulos, vean y toquen la imagen: "Ve en ella cuanto desea / Tomás, y sabio la toca, / y cuando el pincel retoca / la copia, el apóstol diestro / dice que obra de su maestro / le salió a pedir de boca” (vv. 365-370).
} 
señalar que "el tiempo el rigor serena" (v. 335): la lluvia ha cedido y quienes habían retirado los adornos que engalanaban la ciudad por temor al agua, ahora nuevamente los sacan: "y el rico adorno a la calle / echó por cada balcón” (vv. 339 y 340). Si la autora había sido parca al presentar a los peregrinos cuando se dirigían al cerro, no lo es cuando éstos se despiden del Tepeyac y regresan a la metrópoli. Con esta última parte se destaca nuevamente el motivo de la romería guadalupana y se detalla la condición de cada uno de los peregrinos.

La procesión abre con las hermandades, que lucen sus estandartes: agustinos, franciscanos, dominicos, dieguinos, mercedarios, carmelitas y jesuitas (décs. 39 a 49). A cada una de estas órdenes, la cronista le dedica una o dos décimas, en las que elogia a su fundador o santo principal (Agustín, Francisco, Juan de Dios, Pedro Nolasco, Teresa de Jesús, Domingo, Ignacio de Loyola), sus trajes y sus blasones. Hay que destacar que la poetisa regularmente utiliza la perífrasis o alusión para presentar a las órdenes religiosas; mediante algún atributo de sus fundadores, de sus hábitos, santos o insignias, los muestra al lector, quien reconoce a cada hermandad sin que se exprese directamente su nombre.

Siguen a las órdenes el cabildo eclesiástico, los naturales o indígenas, el protomedicato y la Universidad de México, el tribunal del Santo Oficio, el corregidor, la Real Audiencia, caballeros y la guardia real (décs. 50 a 57). Esta última, a decir de González, sobraba, pues en su patria "sobra la fe y la lealtad, / hoy la regia majestad, / con, seguro, en esta acción, / ofreció aqueste escuadrón / sólo por autoridad" (vv. 555-560). Tras ellos se ubican bailarines y danzantes. A diferencia de otras fiestas, donde los disturbios tenían lugar, en esta ceremonia todos ofrecen sus respetos y custodian el carro que lleva la imagen de la Guadalupana a la ciudad. Luces cubren el camino de regreso, pues ha comenzado a oscurecer, y los peregrinos rezan fervientemente el rosario (décima 63). La fiesta 
ha concluido y el poema también, por lo que González recurre a un último tópico literario: la falsa modestia. "Confusa ${ }^{17}$ al perdón anhelo, / pues viendo prodigio tanto, / tanto en su copia me encanto, / que de gozo amor delira, / y me ha hecho parar la lira / ver lo rudo de mi canto" (vv. 675-680).

Ana María González y Zúñiga abre y cierra su poema de manera circular: en su dedicatoria pide benevolencia a la Virgen de Guadalupe por lo rústico de su canto y en la décima 68 suspende su crónica por parecerle que su obra es ruda. Como otros creadores del XVIII, González sigue los tópicos, motivos y metáforas de la literatura grecolatina y del Siglo de Oro. En Nueva Espańa, la corriente barroca se extiende hasta la segunda mitad del Setecientos y convive con otras tendencias, como el neoclasicismo, por lo que muchos autores siguen bebiendo de esta línea y ajustan su lenguaje poético a las diferentes circunstancias que se celebran y festejan a lo largo del XVIII. González toma de su bagaje cultural y literario ciertos elementos y los adapta a un nuevo episodio de la vida novohispana: la jura solemne del patronato de la Guadalupana en Nueva España.

Su poema cronístico se inserta en la tradición de escritos guadalupanos. Los cinco temas que, según Peñalosa, son comunes en la literatura guadalupana (Siglo XX 17) aparecen desarrollados en sus décimas, con algunas variantes: la aparición milagrosa, la figura de Juan Diego, los peregrinos, la descripción de su imagen y las flores para aludir a su retrato, lo cual demuestra que González conocía a la perfección esta tradición. Uno de los mayores aciertos de sus décimas radica en el tratamiento que les da a tres motivos guadalupanos: el retrato detallado que hace de la Virgen en el manto, la

${ }^{17}$ Debe entenderse que la poetisa está confusa, en el sentido de turbada, admirada y pasmada (Diccionario de autoridades, s. v. 'confuso'), por la imagen milagrosa de la Guadalupana (la prodigiosa “copia”), a la cual sus décimas, según su modestia, no alcanzan a hacerle justicia. 
presentación de los peregrinos, mediante la utilización de diversas perífrasis y alusiones, y, finalmente, el uso metafórico que hace del término flor. Otra de las virtudes del texto es la descripción minuciosa de los espacios, objetos y del clima (la ciudad, sus calles, sus casas, la iglesia, los arcos, sus decorados, la iluminación, etcétera: toda la ciudad celebra el patronato en un día lluvioso). En el poema se percibe la mirada detallista de la autora, quien se centra en diversos aspectos y elementos de la fiesta para recrearlos y hacerlos casi vívidos. Esta capacidad de observar casi todo y de poder plasmar en verso aquello que ha mirado atentamente diferencia su escritura de otras crónica guadalupanas del siglo XVIII. ${ }^{18}$

Si bien González fue conocida en su momento como poetisa de certámenes, no hay que olvidar que estos concursos fueron una buena ocasión, a decir de Tenorio, para el ejercicio intelectual y artístico en Nueva España (2010: 22); amén de que tales justas eran uno de los pocos espacios en los que las mujeres podían escribir y ser publicadas. La constancia y calidad poética de la autora determinaron que se le encargara relatar la fiesta de 1747, donde quedó confirmado su ingenio. La poetisa dominaba todos los elementos que eran necesarios en su época para considerar a alguien un buen escritor: manejo y destreza de distintas formas poéticas, tópicos y motivos literarios, figuras bíblicas y mitológicas; también, ingenio para organizar y disponer la materia poética. Parte de estos recur-

${ }^{18} \mathrm{Al}$ respecto, cabe señalar que el poema de González supera en precisión y calidad a la crónica de 1737, un romance escrito por el bachiller Bernardino de Salvatierra y Garnica para relatar la "Jura del patronato de nuestra Seńora de Guadalupe de México", que hizo la Ciudad de México a causa de la peste de matlazáhuatl: el primero de los sucesos memorables guadalupanos del siglo XVIII. De Salvatierra sólo dedica cuatro versos a presentar el manto del Tepeyac y menos de cien para mostrar la celebración del pueblo en honor de la Virgen (véase García, 1947: 57-66). En cambio, la poetisa dedica seiscientos versos para relatar la procesión y las manifestaciones devotas hechas por los novohispanos en 1747. 
sos se mostraron en este estudio, aunque aún queda un trecho que recorrer para tener el panorama completo de su obra poética, poco conocida y estudiada. Este trabajo muestra otra faceta de la autora: la de cronista de fiestas religiosas y civiles, labor que viene a ampliar la visión del papel que tuvo González y Zúńiga como escritora en Nueva España. Quizá el análisis y estudio de sus otros dos poemas cronísticos, los dedicados a relatar las fiestas novohispanas en honor a Fernando VI, la revelen como una destacada cronista en Nueva España. ${ }^{19}$ Además de ser una lectura placentera, su crónica festiva es un buen ejemplo de la producción literaria femenina que floreció en el siglo XVIII novohispano.

\section{Bibliografía}

Baehr, Rudolf, 1997, Manual de versificación española, Madrid, Gredos.

Beristáin de Souza, José Mariano, 1980, Biblioteca hispanoamericana septentrional (1816), edición facsimilar, México, UNAM/ Claustro de Sor Juana.

Biblia, 2001, versión Reina-Valera, revisión 1909, Corea, Sociedades Bíblicas Unidas.

Castro, Francisco de, 2012, La octava maravilla y sin segundo milagro de México, perpetuado en las rosas de Guadalupe y escrito heroicamente en octavas, Alberto Pérez-Amador Adam (ed.), México, FCE.

Cifra feliz de las dichas imponderables que se promete la monarquía española bajo el suspira[do] dominio de su augusto soberano el

\footnotetext{
${ }^{19}$ Como un antecedente de mujeres cronistas, cabe mencionar a Ana Caro Mallén de Soto, quien fue una de las escritoras más destacadas de poesía de relaciones del siglo XVII español; en sus poemas relata diversas fiestas religiosas y civiles celebradas en Sevilla y Madrid.
} 
señor don Fernando VI, 1748, Salamanca, Imprenta de Santa Cruz.

Coloso elocuente que en la solemne aclamación del augusto monarca de las Españas don Fernando (que Dios prospere) erigió sobre brillantes columnas la reconocida lealtad y fidelisima gratitud de la imperial y pontificia Universidad mexicana, 1748, , México, Nuevo Rezado de dońa María de Benavides.

Cruz, sor Juana Inés de la, 1994, Obra selecta, Margo Glantz (ed.), Caracas, Ayacucho.

Eguiara y Eguren, Juan José, 1986, Biblioteca mexicana, t. I, Ernesto de la Torre Villar (ed.), México, UNAM.

García Gutiérrez, Jesús, 1947, Cancionero histórico guadalupano, México, Jus.

Goicoechea, Juan de, et al., 1994, Siete Sermones Guadalupanos (1709-1765), David A. Brading (sel. y est.), México, Centro de Estudios de Historia de México Condumex.

González Acosta, Alejandro, 1995, "Un poema manuscrito guadalupano del siglo XVIII", en José Lucas Anaya, La milagrosa aparición de Nuestra Señora María de Guadalupe de México, Alejandro González Acosta (est., ed. y notas), México, UNAM.

González Fernández, Fidel, 2004, Guadalupe: pulso y corazón de un pueblo, Madrid, Encuentro.

González y Zúñiga, Ana María, 1748, Florido ramo, que tributa en las fiestas de María santísima de Guadalupe la imperial corte mexicana, México, Nuevo Rezado de María de Ribera.

Jiménez de Bonilla, Joaquín Ignacio, José Francisco de Ozaeta y Oro y José Francisco de Aguirre y Espinosa, 1730, El segundo quince de enero de la corte mexicana. Solemnes fiestas, que a la canonización del místico doctor san Juan de la Cruz celebró la provincia de San Alberto de Carmelitas Descalzos de esta Nueva España, México, José Bernardo de Hogal. 
Martin, René, 1998, Diccionario de la mitología clásica, Alegría Gallardo Laurel (trad.), Madrid, Espasa-Calpe.

Mínguez Cornelles, Víctor, 1995, Los reyes distantes: imágenes del poder en el México virreinal, Castelló de la Plana, Universitat Jaume I.

Muriel, Josefina, 2000, Cultura femenina novohispana, México, UNAM.

Osorio Romero, Ignacio, 1991, El sueño criollo. José Antonio de Villerías y Roelas (1695-1728), México, UNAM.

Peñalosa, Joaquín Antonio, 1984, Flor y canto de poesía guadalupana. Siglo XX, México, Jus.

, 1987, Flor y canto de poesía guadalupana. Siglo XVII, México, Jus. , 1988, Flor y canto de poesía guadalupana. Siglo XVIII, México, Jus.

Real Academia Española, 1976, Diccionario de Autoridades, 3 t., Madrid, Gredos.

Sandoval Zapata, Luis de, 2005, Obras, José Pascual Buxó (est. y ed.), México, FCE.

Tenorio, Martha Lilia, 2010, Poesía novohispana. Antología, t. II, México, Colmex/FLM.

Torre Villar, Ernesto de la, y Ramiro Navarro de Anda (comps.), 2007, Nuevos testimonios históricos guadalupanos, t. I, México, FCE.

Vega Carpio, Lope Félix de, 1777, Colección de las obras sueltas, así en prosa, como en verso, t. VI, Madrid, Antonio de Sancha.

Vigil, José María, 1893, Poetisas mexicanas, México, Secretaría de Fomento. 